Carlos Hernán Sosa

Universidad Nacional de Salta

\title{
FRAGMENTACIÓN Y DESCONFIANZA DEL AYER: ESTRATEGIAS PARA RELEER EL PASADO EN DOS NOVELAS ARGENTINAS CONTEMPORÁNEAS
}

\author{
No hay otro tiempo que el ahora, este ápice \\ Del ya será y del fue, de aquel instante \\ En que la gota cae en la clepsidra. \\ El ilusorio ayer es un recinto \\ De figuras inmóviles de cera \\ $O$ de reminiscencias literarias
}

Que el tiempo irá perdiendo en sus espejos.

Jorge Luis Borges, «El pasado».

\section{Introito}

Durante las últimas décadas, se ha escrito una enorme cantidad de textos críticos académicos ${ }^{1}$ dedicados al estudio de la novela histórica -o «nueva novela histórica», en términos de Seymour Menton (1996)-, un género que pródigamente se viene produciendo en Latinoamérica, aproximadamente desde mediados del siglo XX. Proponer un panóptico de este ingente fenómeno escriturario, tanto de la producción literaria como de la concomitante producción crítica, es una tarea monumental que escapa a los intereses más acotados de este trabajo. En realidad, en nuestro abordaje nos interesa rescatar sólo una de las características, reiterada en diferentes textos exponentes de este género, que resulta especialmente relevante en el corpus de análisis que proponemos. Nos referimos a la reconstrucción desmitificadora de la historia, como una perspectiva iterativa dentro de las estrategias discursivas de estas novelas, y su consustancial percepción, muchas veces cifrada, del presente.

Estos nuevos planteos, donde la historia se evalúa, ante todo, como reconstrucción escrita -parcial y estratégica- de acontecimientos pasados, derrumbando las tardías ilusiones objetivistas que había instaurado el paradigma positivista decimonónico, tienen sus orígenes en las redefiniciones epistemológicas que instauró el giro lingüístico, ${ }^{2}$ en el ámbito de las ciencias sociales, a mediados del siglo XX. En este sentido, podemos afirmar que mediante la escritura de las novelas históricas la literatura recupera discusiones comunes de la agenda de las ciencias sociales -provenientes de esferas tan disímiles como la historia o la etnografía-, para generar sus propias revisiones del pasado, naturalmente desde las múltiples potencialidades y la particular densidad hermenéutica que permite la escritura literaria.

¿Cómo releer, entonces, la historia?; ¿Desde qué perspectiva encuadrar una aproximación al pasado, ya no arqueológica -tal como había intentado, en gran medida, la no-

\footnotetext{
1 Sería imposible mencionar la innumerable cantidad de estos trabajos, seleccionamos sólo algunos de los textos más significativos: Seymour Menton (1993), Noé Jitrik (1993), María Cristina Pons (1996, 2000), Tulio Halperín Donghi (1998) y el número especial de Revista Iberoamericana (2005).

2 Para este punto consultar Elías Palti (1998).
} 
vela histórica decimonónica de cuño romántico y, también, algunas líneas del siglo $\mathrm{XX}^{-3}$ sino doblemente significativa -en tanto reconstrucción del pasado e interpretación de los sentidos de nuestro presente-?; ¿Con qué herramientas discursivas operativizar las estrategias que permiten recomponer una versión significativa del ayer?, son algunos de los interrogantes comunes que subyacen en la elaboración literaria de las dos novelas de autores argentinos que nos proponemos analizar en este artículo. En el caso de La mujer en cuestión (2003), de María Teresa Andruetto, la elección del policial, desde una óptica distanciada y crítica, constituye la trama discursiva estratégica para implementar una lectura de la historia argentina reciente; mientras que en Andrés Rivera, Esto por ahora (2005) funda una interpretación, en mosaico, de gran parte de la historia argentina del siglo XX, dislocada por la enunciación deliberadamente fragmentaria del relato. Aunque con asunciones diferentes, ambos textos se hermanan en el convencimiento apesadumbrado y escéptico sobre un pasado moldeado por acciones equivocadas, hasta cierto punto inexplicables, cuyas consecuencias abruman las perspectivas de nuestro presente.

\section{Primera alternativa: el policial revisitado}

El mayor inconveniente que a este informante se le presenta es el reconocimiento de que una persona es en realidad muchas.

María Teresa Andruetto, La mujer en cuestión, p. 31.

La novela La mujer en cuestión $n^{4}$ conjuga dos características, de manera imbricada, que resultan determinantes para encauzar las significaciones globales del relato de Andruetto. En primer lugar, y como anticipáramos, el texto recupera un conjunto de rasgos distintivos del género policial, haciendo especial hincapié en una lectura de los mismos que no rehuye las posibilidades escriturarias que brindan la parodia y el pastiche. ${ }^{5}$ En este sentido, la existencia de un misterio por resolver y la actuación de un investigador que, a lo largo de la narración, intenta acercarse a la verdad, constituyen los elementos medulares más evidentes de la recuperación de la intriga prototípica del policial. ${ }^{6}$ Ahora bien, indagados con mayor detalle, estos elementos no pueden ocultar redefiniciones, nuevas vueltas de tuerca sobre el género, que dan cuenta de una deconstrucción de los modos tradicionales de organización de la trama policial (en sus dos vertientes: clásica y negra).

En el caso del misterio por resolver, verdadero motor de las acciones, especie de cosmos incuestionable alrededor del cual orbitan los personajes y las situaciones del relato, la particularidad que asume en esta novela radica ante todo en su carácter de indefinición. He aquí un primer rasgo paródico. Tanto en el policial clásico como en el de vertiente

\footnotetext{
3 En relación con estas modalidades, dentro de la novela histórica, resulta ineludible la lectura canónica que ha propuesto Georg Luckacs (1977), sobre todo a partir de una revisión de las novelas históricas de Walter Scott.

Este texto de María Teresa Andruetto ganó el Premio Régimen de Fomento a la Producción Literaria Nacional y Estímulo a la Industria Editorial del Fondo Nacional de las Artes de Argentina, para el año 2002, en el rubro novela. El jurado estuvo integrado por Mario Goloboff, María Rosa Lojo y Juan Martini.

5 Para estas formas de intertextualidad seguimos las consideraciones clásicas postuladas por Gérard Genette (1989).

${ }^{6}$ Remitimos a algunas relecturas recientes del género policial: Jorge Lafforgue y Jorge B. Rivera (1995), Daniel Link (2003) y Elvio E. Gandolfo (2007).
} 
negra, la existencia de un hecho -abiertamente reñido con la ley y la moral, según la perspectiva clásica, y desde una percepción general más escéptica o amoral en el policial negro-, funciona como acontecimiento -encuadrado, la mayoría de la veces, en el crimen y/o el robo- cuya resolución se instaura en motor de las acciones, como una suerte de disparador y justificación del inicio de la intriga misma.

La contundencia respecto del hecho ocurrido -no sus detalles (motivos, autores, circunstancias, etc.) que quedarán a merced de las astucias del detective/investigador- resulta sesgada en el texto de Andruetto, pues en definitiva nunca se explicitan los verdaderos motivos de la investigación encarada. Tras la lectura del relato, la única certeza perdurable en este sentido es que el corpus de la novela funciona, elección de género discursivo mediante, como un informe de investigación realizado con el fin de «relevar de un modo exhaustivo el entorno inmediato y las circunstancias de la vida de la mujer en cuestión [Eva Mondino]» (Andruetto, 2003: 11). ${ }^{7}$ Requerida por un «mandante», desconocido para el propio narrador/investigador, los motivos que justificarían la necesidad de recuperar y acopiar estos datos nunca se revelan en la novela.

Rápidamente advertimos, entonces, que estamos en presencia de un ordenamiento de los acontecimientos que por momentos se torna desconcertante y anárquico en la tarea del investigador -y consecuencia en la misma escritura-, pues hay una notoria indefinición respecto de los motivos que regulan dicha investigación. La percepción difusa e ignorante que guía los pasos del investigador está determinada por el hecho de que poseemos un laberinto de vericuetos con los cuales reordenar una historia pasada, pero no sabemos con qué fines, y a ciencia cierta tampoco sabemos, al igual que el investigador, qué elementos priorizar en esta búsqueda. En síntesis, tenemos una investigación que por momentos se muestra claramente deudora de las argucias lógicas y analíticas del policial clásico -incluso en el fraseo de ciertos pasajes, que se aproximan al pastiche- pero, gesto paródico de por medio, no se sabe en verdad qué se investiga.

La propia figura del investigador, cuya genealogía literaria pareciera reconocer más filiaciones con el investigador del policial negro antes que con el detective clásico, denota una construcción como personaje que también evidencia sesgos paródicos. Como muchos de sus antecesores en el género, lejos del rol que cubría el detective de biblioteca como restituidor de un orden moral corrompido por el hecho criminal y desde un raciocinio hiperbólico a veces inverosímil, el investigador de nuestro texto actúa movilizado por cuestiones decididamente más mundanas, en este caso la contratación que le reportará «una suma razonable» (Andruetto, 2003: 11).

Ahora bien, este sabueso desconoce los motivos que determinan el rastreo de su presa pero, como explicita en un comienzo, intentará mantener aún así cierta objetividad en su relato -una tarea desde todo punto de vista imposible, puesto que el informe reviste los rasgos de un complejo collage, elaborado por el entramado de los testimonios- aunque no avanza más allá de la inserción de cierto orden sobre los datos recuperados, que es ya por supuesto un modo de imprimir una significación sobre los acontecimientos mismos. Recordemos que, sin tapujos, el investigador asume el rol de censor de los testimonios cuando, por ejemplo, declara que:

\footnotetext{
7 Significativamente, la narración se abre con el siguiente título «Informe/ realizado a partir del relevamiento/ exhaustivo del entorno inmediato y/ las circunstancias de vida de/ E. M. F.» (Andruetto: 2003, 13); mientras que, en el cierre, se pormenoriza sobre una serie de «Documentación que se adjunta»: 21 cassettes numerados, fotocopias de cartas, fotografías, y nomina de «Personas que accedieron a prestar testimonio sobre Eva Mondito Freiberg, por orden de aparición») (Andruetto: 2003, 117-120).
} 
Algunas de ellas [las personas que han contribuido con información acerca de Eva] no serán presentadas (...) ni transcriptos sus testimonios, (...) ya sea porque no tiene un carácter relevante, ya sea por la necesidad de quien redacta este informe de reducir el campo testimonial (...). (Andruetto, 2003: 66)

A medida que avanza en sus tareas recabando información (a partir de la realización de entrevistas, la recolección de fotografías y algunos pocos materiales escritos como algunas cartas), el narrador/investigador tomará conciencia, en varias oportunidades, de sus propias limitaciones, pues sólo percibe como posible «dibujar un perfil cercano a la verdad» (Andruetto, 2003: 31); por ello, quizás, incluso se permitirá la salvedad de emitir juicios «a riesgo de ser subjetivo» (Andruetto, 2003: 22). De este modo, la imposibilidad de preservar un poco de objetividad, de un necesario distanciamiento capaz de permitir la mirada «aséptica» sobre los hechos, es otra prueba de la presencia de una lectura paródica sobre los desempeños de la figura tradicional del investigador; en este caso, porque el privilegiado recolector de las piezas del rompecabezas explicita sin pudor sus limitaciones y -lo que constituiría una debilidad imperdonable desde los fundamentos del policial clásico- reconoce sin pesar alguno la inherente imposibilidad de llegar a la verdad. El colmo de las limitaciones, en este sentido, es su declaración en el final de la novela, donde concluye respecto de su infructuosa acción al frente de la investigación:

Este informante comprende hoy que ése es un propósito imposible de lograr (...) y que nunca se podrá saber del todo quién es Eva Mondino, si es verdad que llevó a cabo ciertas acciones que algunos le adjudican y, en ese caso, por qué razón o bajo qué condiciones lo hizo. (Andruetto, 2003: 114-115)

Sin una finalidad prescrita con claridad y con una autoconciencia sobre las imposibilidades inherentes del oficio, las dos deudas más notorias con el policial a las cuales aludimos en un comienzo (el misterio por resolver y la labor de investigación) aparecen evidentemente deconstruidas por la novela, desde una nueva perspectiva que pone su énfasis en subrayar las aristas más insostenibles del género.

El segundo aspecto, cuyo tratamiento creemos merece subrayarse en la novela de Andruetto, es la relectura de la historia argentina reciente que nos propone, a partir del despliegue de nuevas estrategias narrativas que seleccionan la trama del policial para representar los acontecimientos históricos.

A diferencia de la indefinición que caracterizaba los móviles de la investigación, a la hora de acercar los cronotopos que enmarcan el relato, el texto es generoso en datos que sitúan la acción subrayando un especial interés por lo ocurrido en la ciudad de Córdoba, en el período previo y durante la última dictadura militar en la Argentina. En este sentido, rastrear pistas para reconstruir la vida de una persona tiene como trasfondo mayor la reconstrucción de todo un período histórico. Este modo trabado que entreteje la historia personal, privada e íntima, con los acontecimientos públicos, sociales y políticos de toda la nación constituye una de las tácticas más relevantes para releer nuestro pasado. Quizás en este cruce se esconda una alegoría, sobre las razones de existencia de la propia narración, donde encontraríamos los ocultos motivos de la investigación que el propio investigador desconoce: parecería importar menos la historia personal de la mujer en cuestión que el panorama histórico que su figura permite recomponer, aunque de manera parcial y escurridiza. 
Respecto de la elección del punto de vista ideológico, político, desde el cual se presentan los hechos, resulta sintomático que a pesar de que se selecciona a una militante comunista y su itinerario de vida para reconstruir el período, no hay un compromiso efectivo que permita organizar una lectura reivindicadora de los grupos de disidentes o de resistencia a la dictadura militar. Aquella indefinición, que comentábamos anteriormente en el orden genérico, contamina también la perspectiva de análisis de la historia reciente, por lo que también parecen tomarse los recaudos necesarios para evitar posicionamientos comprometidos que configurarían discursos legitimadores donde se tomaría partido por alguno de los puntos de vista encontrados sobre el período.

La mención de las persecuciones ideológicas, las detenciones clandestinas, la tortura y la desaparición de personas, la sustracción de menores, configuran en verdad una imagen contundente sobre el terrorismo de estado contemporáneo (la elección del policial, como género asociado al crimen, fomenta esta imagen), pero se solapa cualquier consideración o cuestionamiento crítico al respecto $;{ }^{8}$ quizás, luego de los constantes trabajos en el orden de los imaginarios sociales, por la recuperación de la memoria y una política contra el olvido de los hechos implicados durante este período, en la Argentina, la explicitación del compromiso se torne innecesaria por obvia.

Probablemente, esta perspectiva sea también una estrategia empleada para poder volver sobre cuestiones, socialmente tan traumáticas, como las que caracterizaron la dictadura militar en el país. La mirada final de la novela, en este aspecto, parece indicarnos que frente al dolor que representa todavía la recuperación de estos hechos, es necesario un abordaje que resulte lo menos desgarrador posible, y es por ello que se opta por caminos que, sin ser condescendientes con los crímenes cometidos, se tornan alusivos y menos directos.

Es notorio, asimismo, una evidente puesta bajo sospecha de las interpretaciones maniqueas. La caracterización «indecidible» de la protagonista parece así significativa, puesto que su figura reviste alternativamente tanto los rasgos de la víctima, por ser una detenida por motivos políticos, como los del victimario, tras la sugerencia reiterada sobre la delación de sus compañeros, que aflora a lo largo del relato. Estos roles intercambiables contribuyen también a suspender defensas unanimistas.

Finalmente, podemos agregar que La mujer en cuestión promueve una imagen de lector modelo eminentemente activo, pues éste debe a cada momento suturar las parcialidades con las cuales el narrador/investigador recompone la intriga en torno a la personalidad y a la vida de Eva Mondino. Esta participación constante lo habilita, a su vez, como el último cómplice y/o juez de las vicisitudes que nos presenta la historia. Esta fragmentación, que no deja lugar a relecturas orgánicas, íntegras, es uno de los rasgos posmodernos más evidente con el cual construye su punto de vista narrativo la novela de Andruetto.

Como fiel correlato de la fragmentación, el escepticismo que impera por las páginas tampoco deja en pie lecturas monolíticas; no resultan aptas para dirimir sobre las acciones de la intriga o sobre los personajes, y tampoco parece posible recomponer una interpretación del pasado nacional argentino que arriesgue, con decisión y responsabilidad, una

\footnotetext{
8 Resulta interesante confrontar esta perspectiva de revisión de la historia con la encarada por toda otra línea narrativa en la Argentina, con matices muy diversos desde los aportados por Ricardo Piglia hasta los de Osvaldo Soriano, de la cual se distancia abiertamente este texto de Andruetto. Como presentación de esta línea de contraste, resulta útil el tomo colectivo (AAVV, 1987) dedicado a la narrativa producida durante la última dictadura militar en Argentina.
} 
lectura de los acontecimientos recientes en el marco de la última dictadura militar. Insistimos, quizás no hay tibieza en el planteo sino una opción articulada desde el desencanto que provoca abordar estos temas urticantes, como un síntoma del descrédito o de la resignación ante prácticas sociopolíticas que desde el presente siguen, vía corrupción política e injusticia social, recordando en buena medida las atrocidades de nuestro pasado.

\title{
Segunda alternativa: fragmentación y montaje
}

\begin{abstract}
¿Qué había que respetar las leyes de tránsito, y asistir a las fiestas escolares el 25 de mayo y el 9 de julio, y cantar, la voz sonora, las estrofas del Himno Nacional, mientras se iza la bandera azul y blanca, bendita sea entre las banderas que lo son?.
\end{abstract}

Andrés Rivera, Esto por ahora, p. 105.

En consonancia con varios aspectos del texto de María Teresa Andruetto, la novela Esto por ahora (2005), de Andrés Rivera, organiza sus significaciones mediante la articulación de complejos procedimientos narrativos con una lectura de la historia argentina, que promueve una percepción astillada del pasado. ${ }^{9}$ Nuestra hipótesis vislumbra esta circunstancia como una simbiosis donde se aúnan, bajo una común expresión fragmentaria y disgregada, las estrategias narrativas y la revisión histórica, entrelazadas para enarbolar también una radiografía, políticamente escéptica, sobre nuestro presente.

En principio, interesa subrayar la organización «caleidoscópica» que este texto de Rivera elige para narrar los acontecimientos; la misma funciona organizando una variada y compleja red de significaciones que van conformándose a partir de la presencia de diversas estrategias de enunciación. Destacamos, para comenzar, la presencia de los diferentes narradores (Lucas, Daiana, Arturo Reedson, el narrador omnisciente en tercera persona). Si bien los capítulos aparecen titulados con los nombres de los personajes, como un modo directo de señalar el «dominio» de dicha voz narrativa en esa sección del texto, se producen diferentes intromisiones del narrador omnisciente que fisura el punto de vista de los personajes, lográndose como resultado un verdadero coro de voces -sin jerarquías, aunque podría marcarse una preeminencia de la voz de Arturo Reedson- que se reparte enunciaciones parciales del relato.

Esta organización muy elaborada de la narración hecha mano frecuentemente de las técnicas de la fragmentación y el montaje, una herencia de la experimentación narrativa ampliamente trabajada en la novela argentina contemporánea, ya desde las primeras obras de Manuel Puig, como La traición de Rita Hayworth (1968) y Boquitas pintadas (1969). En este sentido, la utilización de fragmentos, de verdaderas «porciones» discursivas foráneas, insertas en el nuevo contexto de estructuras narrativas con perfiles más tradicionales, contribuye a generar disparadores de sentidos que vuelven polivalentes estas incorporaciones textuales. Pensemos, por ejemplo, en el funcionamiento de la breve frase:

9 La historia de los personajes de Esto por ahora (2005) se continúa en otra novela posterior del autor: Punto final (2006). Rivera ya había ensayado esta modalidad de «narración en díptico», en una bilogía anterior: El amigo de Baudelaire (1991) y La sierva (1992). En tanto que nos interesa analizar en detalle los procedimientos compositivos de Esto por ahora, sólo tendremos en cuenta ésta novela y no consideraremos su continuación en Punto final. 
«Vero te amo/AMSORRY» (Rivera, 2005: 20), que cierra la narración del primer capítulo del texto a cargo del enunciador en tercera persona, quien relata el encuentro de Leonel y Facundo en el bar, mientras ultiman el asesinato de Reedson. Inicialmente, hay que reponer la aparente ubicación de la frase, que fácilmente podríamos interpretar como un grafitti inscripto en la mesa sobre la cual toman café los personajes -o quizás en algún otro lugar visible desde la ventana para los interlocutores: la calle, una pared, etc-. La frase, que en primera instancia puede parecer un gesto verista-verosimilista del relato permite en realidad, gracias a las posibilidades disparadas por el montaje, una interpretación trabada con todo el capítulo en ciernes; a partir de ésta puede entenderse como una alusión indirecta al estado anímico de Leonel, quien fantasea mientras dialoga con Cara'iguante con una relación incestuosa con su hermana Daiana, o incluso podemos estar en presencia -y esto lo sabremos muy avanzado el texto- de una pista por ahora incomprensible para el lector, quien descubrirá más adelante el vínculo afectivo entre Cara'iguante y Daiana. Apelando a estos juegos de significación, la articulación entre fragmentación y montaje, a lo largo de toda la obra, explota las operaciones cruzadas que estas incorporaciones [pseudoavisos clasificados: «Ni golpe/ ni nada/ Gatúbela coge de parada/ tratar aquí» (Rivera, 2005: 28); carteles en la vía pública: «COMIDAS RÁPIDAS» (27), «CAFÉ Y DOS CRIOLLITOS. 2.30» (31), refranes: «ESCAPAN LOS COBARDES/ UNOS PARA DELANTE/ OTROS PARA ATRÁS» (27) y las perversiones de refranes: «DIOS APRIETA PERO NO AHORCA./ ESTRANGULA» (55), citas de autores literarios: «PIENSO QUE NUNCA MÁS/ VOLVERÁ A HABLAR/ WILLIAM FAULKNER» (88), «iHE AQUÍ EL TIEMPO DE LOS ASESINOS!/ Iluminaciones/ ARTHUR RIMBAUD» (100), etc.] potencian con vistas a conseguir el humor, la ironía, la parodia, o la amplificación de los sentidos serios en la lectura.

Esta elección narrativa, que recompone un todo a partir de pequeñas piezas discursivas, se aproxima también a la técnica del bricolage, porque rescata una serie de materiales de deshecho -o por lo menos de una estimación marginal dentro de las ponderaciones tradicionales de los géneros discursivos en la literatura-, como es el caso de los carteles de propaganda callejera, los avisos clasificados o los grafittis, para subsumirlos en un nuevo proyecto discursivo que, en las antípodas de lo esperado, genera un producto narrativo altamente complejo y cuyo abordaje exige una lectura demandante y siempre provocadora.

Otro elemento, que contribuye a desplegar las constantes generadoras de sentido en la novela, es el uso calculado de un cúmulo de paratextos $;{ }^{10}$ creemos que merecen «destacarse dos empleos particulares. Ante todo el uso de los epígrafes, constituidos generalmente por fragmentos de poemas de autores argentinos contemporáneos, especialmente poetas (Juana Bignozzi, Guillermo Saavedra, Roberto Raschella, Juan L. Ortiz), y algunos otros textos de autores extranjeros (Philip Roth, Mao Tse-Tung y Enrique Lallemant). En estas circunstancias, los epígrafes conjugan su función paratextual, tal como lo entiende Genette (2001), como auténticos umbrales de significación de cada capítulo; por ejemplo, en el caso de «El velador» de Saavedra (Rivera, 2005: 57), que anticipa la temática de la muerte de la madre de Reedson que se contará a continuación. Al mismo tiempo, y promediando la lectura, los epígrafes pueden abonar significaciones mayores de todo el texto; es el caso del fragmento de «Interior con poeta» de Bignozzi, donde se constata una amarga reflexión sobre la militancia política de izquierda, pues el yo lírico ve estrellarse sus

\footnotetext{
${ }^{10}$ Para ponderar las significaciones que articulan los paratextos, tomamos en cuenta las consideraciones de Gérard Genette (2001) y Maite Alvarado (1994).
} 
expectativas: «tengo ante los ojos una pared impenetrable/ detrás de la cual sólo hay/ otros 50 años de trabajo y espera» (Rivera, 2005: 35), y que puede vincularse con una de las constantes sobre el desencanto acerca de la participación política que signa la novela.

Además de estos paratextos verbales, que comentamos sucintamente, existe un segundo uso paratextual de vital importancia para el relato. Me refiero a los paratextos icónicos, representados por variaciones en la grafía, en el tamaño de las letras, por el uso de itálicas y, sobre todo, por los recurrentes espacios en blanco de la página, que en su conjunto diagraman toda una poética del manejo escriturario de la página. Entre las utilidades que representan estos elementos, resulta significativo el rol de «distorsionadores» de la continuidad narrativa que desempeñan las secciones en blanco, como insistentes «empalmes» entre las voces narradoras y entre los géneros discursivos incorporados en la novela. Éstos últimos facilitan rápidos reconocimientos por parte del lector, por ejemplo, de un género discursivo como la historia clínica, bajo cuyas convenciones sociales escuetas y minadas de tecnicismos médicos- se relata la muerte de la madre de Reedson; similar funcionalidad puede apreciarse, asimismo, en el caso de las cartas inicialadas que la mujer de Reedson le escribe a su amante -que muestran un despliegue, almibarado y lastimero, del registro fosilizado de las cartas intercambiadas entre amantes.

Reconsiderando lo expuesto, debemos subrayar que la posición asignada al lector bascula, entonces, entre el asombro que provoca la densidad de estrategias compositivas de un texto que atenta contra los modos tradicionales del relato, y el reconocimiento aliviador de guiños cómplices como los que le acercan las convenciones familiares de los géneros discursivos. Sin embargo, el conjunto de procedimientos narrativos dibuja la imagen de un lector modelo altamente especializado en la recomposición y reposición de los sentidos, ávido manipulador de las insinuaciones y los subterfugios con los cuales opera la trama novelesca, donde se lo instaura -tal como ocurría en la novela de Andruettocomo el último evaluador de un demandante rompecabezas textual. A tal punto parece imponerse esta asignación participativa para el lector que, a medida que llegamos a los últimos capítulos, los mismos parecen ponernos frente a una última prueba, pues van reduciendo su extensión y acentuando su densidad compositiva en cuanto a estrategias -la fragmentación y el tono lírico ocupan aquí un lugar preponderante-; una circunstancia que parece acercarnos un gesto final de confianza, tras el entrenamiento que nos propuso la novela: si hay mayor densidades en el final es porque ya hemos superado un aprendizaje con el cual acreditar mayor perspicacia en la lectura.

Ahora bien, Ecuáles son las utilidades que representan estos procedimientos, que demandan el cuestionamiento y la reticencia, en relación con la historia que Esto por ahora nos cuenta?

En la novela se cruzan dos historias, circunscriptas a dos sujetos que aglutinan otros personajes satelitales: por un lado, la historia de la víctima, Arturo Reedson (y las de su esposa, su madre, su hijo, Pablo Eclert, etc.), por otro, la del asesino, Leonel (y las de Daiana, Facundo alias Cara'iguante, Don Benavídez). Ambas historias se relatan de manera fragmentada y con variados vaivenes temporales, al punto que sólo en el final, con la breve confirmación de la muerte de Reedson, conocemos la vinculación entre ambas secuencias; un modo estratégico de dosificar la intriga que Rivera ya había probado en una de sus novelas anteriores, El profundo sur (1999).

En la seguidilla de cronotopos que amojonan los episodios de la obra, se avanza por un recorrido heterogéneo, desordenado y confuso, que, si bien juega con distancias temporales y espaciales, puede volverse coherente si consideramos la reiterada presencia de 
un acto prototípico que obliga a una participación social. Ya sea con fines liberadores, frente a la invasión extranjera (como es el caso de la historia de la madre de Reedson, en la Polonia invadida por la Rusia comunista); de reivindicación sindical (el caso de Reedson niño acompañando a su padre en una manifestación, en Argentina durante mayo de 1937, y luego como delegado de los tejedores, durante el bombardeo a Plaza de Mayo en 1955); o frente al terrorismo de estado (la defensa de Pablo Eclert, asediado durante la dictadura argentina en 1977), cada episodio parece reiterar pues esta misma circunstancia.

En cada uno de estos hechos resulta notoria la reiteración de actos donde la legalidad se ve corrompida por distintos factores, muchos de ellos capitaneados desde el propio Estado como institución, especialmente en el caso de los sucesos ubicados a lo largo de la historia argentina. La utilidad del delito como un medio para recomponer toda una interpretación sobre los funcionamientos de la vida sociopolítica de la Argentina -tal como lo ha modelizado Josefina Ludmer (1999), en sus estudios sobre genealogías literarias-, permite reconstruir una representación de la vida nacional digitada por la imposición de la ley, donde se ubican tanto la participación de los ejecutores de la misma como la de aquellos que delinquen. En este sentido, la criminalidad de la vida política, en la Argentina del siglo XX, parece ser una de las constantes sobre las cuales dirime, de manera cuestionadora, esta obra de Rivera. ${ }^{11}$ Las represiones policiales durante las manifestaciones obreras, los bombardeos «libertadores» antiperonistas del año 1955, los asesinatos ejecutados durante la última dictadura militar iniciada en 1976, funcionan como el telón de fondo de todo el texto. Frente a esta neurótica constancia de nuestra vida nacional, el crimen de Reedson -una aparente víctima circunstancial de los escarceos pasionales- pierde peso, se minimiza, aunque por ello no deja de funcionar como una forma de relato especular, que mediante un juego de puesta en abismo -que va del asesinato por encargo y por motivos pasionales al crimen organizado desde el Estado- nos sobreimprime la misma figura recurrente de la inestabilidad de las leyes y la ambivalente moralidad que regula la vida política de nuestro país.

La historia de la muerte de Reedson, un idealista en última instancia, equivale así a una parábola donde se nos sacude sobre nuestras formas de encuadrar las prácticas sociales y la necesidad de autorregular nuestra vida pública. Una oscura moraleja parece encerrar el descrédito y el escepticismo que venimos subrayando, ejemplificado con un cúmulo de episodios que no han podido llegar a buen puerto, y cuya persistencia ignominiosa parece sugerirse en la perspectiva futurista del título mismo de la novela: Esto por ahora.

Nuestro orden en esta exposición sobre el texto de Rivera (presentando primero las estrategias y luego un comentario sobre las temáticas abordadas) no resulta gratuito. Confiamos en que el cómo se cuenta la historia resulta más significativo que la historia misma; ya que incluso el acto de repasar el plafón de las estrategias narrativas empleadas nos resulta útil para generar las significaciones de orden temático. De este modo, la fragmentación narrativa es un camino que deriva hacia una percepción inorgánica y fluctuante de los acontecimientos referidos, mediante un permanente retaceo que genera inestabilidad en el propio lector quien siempre tiene la sensación de que le está faltando una pieza. Este tambaleo en la experiencia de lectura, durante los avatares narrativos, parece reconocer en distintos momentos la urgencia por asignar -y estabilizar- sentidos frente a lo que se está contando, y para ello los juegos intertextuales aportan decidida colaboración.

\footnotetext{
${ }^{11}$ Para complementar estas apreciaciones remitimos a los siguientes trabajos: Carlos Dámaso Martínez (1985), Andrés Rivera (en AAVV, 1995: 44-66) y Juan González Moras y otros (1998).
} 
Con este fin abundan en la historia menciones, muchas veces atropelladas y sin aparente razón de ser, de obras y citas literarias, de autores, y también de películas, actores y actrices, que irrumpen en medio de la narración, de las cavilaciones de los personajes o en los fragmentos discursivos menores montados en el relato. ¿Qué papel desempeñan estas intromisiones? Podemos arriesgar que estas formas de intertextualidad con la literatura y el cine contribuyen en la recuperación de sentidos que la organización «caleidoscópica» de la obra dispersa pero que, en última instancia, aspira alcanzar. Estas menciones asignan significados y generan estabilidad pues remiten a circunstancias conclusas, por lo mismo estables y conocidas; tienen el sabor, para los personajes y el mismo lector, de una intersección con la realidad nuestra de todos los días, parecen anclar un sentido común que nos orienta, terminan contextualizando como lo hace la mención de marcas comerciales (Philip Morris), siglas de organizaciones sindicales (CGT) o barrios de la ciudad de Buenos Aires (Villa Lynch). Sin embargo, este anclaje no persigue una mera aspiración verosimilista, datable, como es el caso de los ejemplos anteriores, quizás resulte más útil interpretarlo como una forma de escape autorreferencial: quizás en Rimbaud, en Flaubert, en Miller, en Payró, en García Lorca, en Faulkner, se oculte la estabilidad de sentidos que el texto de Rivera se obstina en entregarnos, y estas menciones constituirían un modo de sutil aseveración que nos insinúa que los sentidos perdurables no pueden encontrarse en las inestabilidades de la realidad, sólo se cobijarían en la red de resignificaciones que la literatura propicia.

\section{Coda}

Como comentario final, debemos subrayar que a pesar del escepticismo y el descrédito que, mediante sus peculiares juegos discursivos plantea cada una de estas novelas, resulta incuestionable en ambas la pretensión última de conseguir una significación que dote de sentido nuestras acciones pasadas. La escritura literaria se resiste pues, aunque dé manotazos y gesticule dubitativa, a perder su prerrogativa de agente modelizador de prácticas socioculturales, desde la promoción de sentidos capaces de incidir en los imaginarios sociales.

De esta manera, elegir entonces una lectura del pasado es siempre un modo, más o menos solapado, de promover una interpretación de nuestro presente y de programar andariveles para los desplazamientos futuros. Tal como entendía Raymond Williams (1980) la noción de tradición, como una selección y organización, para nada ingenua, de aquellos aspectos de las vivencias pasadas que, sobre todo hoy, nos resultan operativas, las dos novelas de estos autores argentinos contemporáneos recortan experiencias de la historia reciente para ayudarnos a decodificar los inconvenientes crónicos que continúan viciando las espurias formas de llevar adelante las prácticas políticas, al tiempo que no escatiman las moralejas que señalan un camino para evitar estos mismos y tan conocidos errores. 


\section{BIBLIOGRAFÍA}

AAVV (1995): La historia y la política en la ficción argentina. Santa Fe: Universidad Nacional del Litoral.

AAVV (1987): Ficción y política. La narrativa argentina durante el proceso militar. Buenos Aires: Alianza Editorial / Institute for the Study of Ideologies \& Literature, University of Minnesota.

Alvarado, Maite (1994): Paratexto. Buenos Aires: Publicaciones del Ciclo Básico Común, Facultad de Filosofía y Letras, Universidad de Buenos Aires.

Andruetto, María Teresa (2003): La mujer en cuestión. Córdoba: Alción.

Gandolfo, Elvio E. (2007): El libro de los géneros. Ciencia ficción. Policial. Fantasía. Terror. Buenos Aires: Norma.

Genette, Gérard (2001): Umbrales. México: Siglo XXI.

Genette, Gérard (1989): Palimpsestos. La literatura en segundo grado. Madrid: Taurus.

González Moras, Juan; Scafati Alfón, Fernando y Rodríguez, Esteban (1998): «En el páramo de la derrota. Conversación con Andrés Rivera». En: La grieta, 4, 60-69.

Halperín Donghi, Tulio (1998): El espejo de la historia. Problemas argentinos y perspectivas latinoamericanas. Buenos Aires: Sudamericana.

Jitrik, Noé (1995): Historia e imaginación literaria. Las posibilidades de un género. Buenos Aires: Biblos.

Lafforgue, Jorge y Rivera, Jorge B. (1995): Asesinos de papel. Ensayos sobre narrativa policial. Buenos Aires: Colihue.

Link, Daniel (compilador) (2003): El juego de los cautos. Literatura policial: de Edgar A. Poe a P. D. James. Buenos Aires: La marca.

Luckacs, Georg (1977): La novela histórica. México: Era.

Ludmer, Josefina (1999): El cuerpo del delito. Un manual. Buenos Aires: Perfil.

Martínez, Carlos Dámaso (1985): «Historia entre la razón y el delirio». En: Punto de vista, VII, 24, 37-38.

Menton, Seymour (1993): La nueva novela histórica de la América Latina, 1979-1992. México: Fondo de Cultura Económica.

Palti, Elías José (compilador) (1998): «Giro lingüístico» e historia intelectual. Bernal: Universidad Nacional de Quilmes.

Pons, María Cristina (2000): «El secreto de la historia y el regreso de la novela histórica». En: Jitrik, Noé (director). Historia crítica de la literatura argentina. Vol. 11 «El oficio se afirma» (directora del volumen Elsa Drucaroff). Buenos Aires, Emecé, 97-116.

Pons, María Cristina (1996): Memorias del olvido. La novela histórica de fines del siglo XX. México: Siglo XXI.

Revista Iberoamericana, vol. LXXI, $\mathrm{n}^{0} 213$ (Dedicado a «Héroes de papel: avatares de una construcción imaginaria en América Latina»), octubre/diciembre de 2005.

Rivera, Andrés (2006): Punto final. Buenos Aires: Seix Barral.

Rivera, Andrés (2005): Esto por ahora. Buenos Aires: Seix Barral.

Rivera, Andrés (1999): El profundo sur. Buenos Aires: Alfaguara.

Rivera, Andrés (1992): La sierva. Buenos Aires: Alfaguara.

Rivera, Andrés (1991): El amigo de Baudelaire. Buenos Aires: Alfaguara.

Williams, Raymond (1980): Marxismo y literatura. Barcelona: Península. 


\section{FRAGMENTACIJA IN SUMNIČENJE VČERAJŠNJEGA DNE: \\ STRATEGIJE ZA PONOVNO BRANJE DVEH SODOBNIH ARGENTINSKIH ROMANOV}

Članek analizira način, kako sodobna argentinska romana, La mujer en cuestión (2003) Maríe Terese Andruetto in Esto por ahora (2005) Andrésa Rivere, prikazujeta dve novi branji preteklosti. Kot predstavnika novega zgodovinskega romana v Latinski Ameriki z različnimi diskurzivnimi strategijami (značilnostmi detektivskega romana, fragmentacijo, montažo, bricolage, medbesedilnostjo, itd.) prikazujeta različna branja zgodovine, še posebej argentinske. Ceprav se romana razlikujeta glede izbranih pripovednih postopkov, s katerimi želita doseči svoj namen, oba rišeta skeptične podobe argentinske zgodovine in postavljata pod vprašaj mnoge zgodovinske dogodke ter tako z nejevero okužita neotipljive zaznave sedanjosti. 